\title{
Modified Blaney-Criddle method — an empirical approach to estimate potential evaporation using air temperature
}

\author{
G. Zhan Barrick Gold Corp., United States of America \\ M. Lin Shelp Barrick Gold Corp., United States of America
}

\begin{abstract}
Potential evaporation (PE) or potential evapotranspiration (PET, $E T_{0}$ ) is one of the fundamental elements in the hydrologic cycle. The Blaney-Criddle $(B-C)$ method is the simplest approach for estimating PE as it requires only temperature data for input. It has been found that the $B-C$ method can provide accurate estimates for moderate climates. Under extreme climatic conditions the B-C method is inaccurate.
\end{abstract}

This paper presents a modification to the original $B$-C method which was calibrated to the observed meteorological data at Barrick sites. The modified method estimates PE with improved accuracy and is applicable to a wide range of climate conditions (from $300 \mathrm{~mm} / \mathrm{y}$ in humid climates to $4,000 \mathrm{~mm} / \mathrm{y}$ in arid climates) and wind regimes.

The proposed approach will provide a simple and practical PE (PET) estimation tool for mining engineers and hydrologists when dealing with mine-wide water management during life-of-mine and closure planning.

\section{Introduction}

Evaporation is one of the fundamental elements in the hydrologic cycle. It is a required parameter for mine water management during both operational and closure phases, used to compute water balances for water ponds, pit lakes and tailings pools. The following three evaporation terms are frequently encountered.

\subsection{Potential evaporation}

Evaporation is the process whereby liquid water is converted to water vapor and removed from the evaporating surface. PE is defined as the amount of evaporation from a large uniform land surface with adequate moisture, such that available energy is the limiting factor. Actual evaporation can equal PE after a rainfall or when ground is covered by dew. In a dry environment, actual evaporation from a land surface is less than PE because the supply of water is limited. In a wet environment, by contrast, available energy is the limiting factor and actual evaporation is usually equal to PE.

\subsection{Potential evapotranspiration}

Evapotranspiration is the loss of water from a vegetated surface through the combined processes of plant transpiration and soil evaporation. Most methods of computing evapotranspiration use meteorological data to provide an estimate of reference (or potential) evapotranspiration. $\mathrm{ET}_{\mathrm{o}}$ is calculated assuming a hypothetical grass crop with specified characteristics such as an albedo of 0.23 , crop depth of $12 \mathrm{~cm}$, and bulk surface resistivity of $70 \mathrm{~s} / \mathrm{m}$. Evaporation reported by automatic weather stations is usually $\mathrm{ET}_{\mathrm{o}}$ calculated using the Penman-Monteith-FAO method (FAO, 1998). Actual ET for a specific crop is estimated by multiplying ETo by a crop coefficient $\left(\mathrm{K}_{\mathrm{c}}\right)$ which depends on the type, height and coverage density of the crop.

In most cases, $\mathrm{ET}_{\mathrm{o}}$ values can be considered equal to evaporation from a large body of water (Brustaert, 1982; Jensen, 1973; Hill et al., 1983). However, for smaller, shallower bodies of water this relationship may not apply. Many factors affect lake/pond evaporation including surface area, depth, water temperature, and turbidity. To date, not enough research has been done to determine the minimum size of water body for which evaporation is approximately equal to $\mathrm{ET}_{0}$. 


\subsection{Pan evaporation}

Most evaporation pans in the US are "Class A" pans made of unpainted galvanised iron or stainless steel, $122 \mathrm{~cm}$ in diameter and $25.4 \mathrm{~cm}$ deep. The pans are supported on low wooden frames and are usually maintained at $20 \mathrm{~cm}(80 \%$ of depth) of water. In humid regions, where advective heat transfer is insignificant, pan evaporation generally gives a realistic estimate of PE. In arid regions, however, where the surrounding air tends to be drier and hotter, pan evaporation often overestimates PE. This is known as the "oasis effect". To estimate $\mathrm{ET}_{\mathrm{o}}$, or PE, from pan evaporation, a pan coefficient $\left(\mathrm{K}_{\mathrm{p}}\right)$ is estimated based on the fetch distance around the pan, wind speed and relative humidity $(\mathrm{RH})$. As a rule of thumb $\mathrm{K}_{\mathrm{p}}$ may be estimated at 0.75 in winter or in cooler periods and 0.65 in summer or in warmer periods. In an extreme cold and humid environment $\mathrm{K}_{\mathrm{p}}$ could be as high as 1.0.

\section{$1.4 \quad \mathrm{PE} / \mathrm{ET}_{\mathbf{0}}$ estimation}

There are direct and indirect methods to estimate PE. Pan evaporation is considered a direct measurement of atmospheric evaporative power. However, operation of evaporation pans is difficult and labour-intensive. In addition, pans cannot be operated in freezing conditions and readings are often complicated by rainfall.

Many indirect methods for estimating PE have been widely used. Input requirements vary in complexity, ranging from single input (temperature only) to multiple inputs (temperature, wind speed, humidity and radiation data). Selection of the most appropriate method for a given situation generally depends upon the availability of data and the ability of the method to estimate both the magnitude and variability of evaporation. Methods employing multiple inputs are usually considered the most accurate. However, in many situations, long-term records of daily temperature may be available whereas wind, humidity, and radiation data are often limited.

Four indirect methods with different input requirements are listed in Table 1. All of these formulas except the B-C method have theoretical formulations based somewhat on Penman's (1948) derivations but with different simplifying assumptions. The Penman-Monteith and B-C methods are normally used for estimating reference $\mathrm{ET}_{\mathrm{o}}$.

To overcome the ambiguity between $\mathrm{ET}_{\mathrm{o}}$ and $\mathrm{PE}$, which mostly originates from biological control of transpiration, this paper adopts the notion that the two are nearly equivalent.

Table 1 Data requirements of different evaporation estimation methods

\begin{tabular}{lccccl}
\hline Method & Temperature & Humidity & Wind & Radiation & Reference \\
\hline Blaney-Criddle & $\mathrm{X}$ & & & & Blaney and Criddle, 1950 \\
Stewart-Rouse & $\mathrm{X}$ & & & $\mathrm{X}$ & Stewart and Rouse, 1976 \\
deBruin & $\mathrm{X}$ & $\mathrm{X}$ & $\mathrm{X}$ & & deBruin, 1978 \\
Penman-Monteith & $\mathrm{X}$ & $\mathrm{X}$ & $\mathrm{X}$ & $\mathrm{X}$ & Monteith, 1965 \\
\hline
\end{tabular}

The B-C method is the simplest approach and requires only temperature data. It therefore provides more opportunity for PE estimation in situations where detailed meteorological records are not available.

In the past, many studies attempted to develop site specific adjustments to the B-C method (Papadopulou et al., 2003; Harmsen et al., 2003; Al-Darir and Aldoubiat, 2005). Results of these studies are only useful for the specific locations studied. The objective of this study is to determine adjustment factors for different types of climate conditions by calibrating the original B-C equation against evaporation records at Barrick sites world-wide. The assessment of the method performance, across a wide range of climate conditions, is believed to be valuable in identifying critical variables that cause most of the variation in PE. This paper presents a modification to the original B-C method, calibrated using observed meteorological data at Barrick sites. 


\section{$2 \quad$ Principles and methodology}

\subsection{Theory and assumptions}

The connection between PE and air temperature $\left(T_{a}\right)$ is rooted in basic physics. Evaporation is a process by which liquid water molecules become water-vapour molecules in the atmosphere. The pressure at the waterair boundary resulting from molecular motion in the direction of escape from the liquid is called the vapour pressure $\left(e_{a}\right)$. There is a limit to how much water vapour can be held in the atmosphere. As more water vapour enters the atmosphere, vapour pressure increases. The higher the temperature of the atmosphere, the more water vapour it can hold. When the maximum vapour pressure is reached, no more (net) water can enter the atmosphere. At this point, we say that the atmosphere is completely saturated and the corresponding vapour pressure is called the saturated vapour pressure $\left(\mathrm{e}_{\mathrm{s}}\right)$.

The rate of evaporation from the water-air interface is determined by the deficit of vapour pressure $\left(e_{s}-e_{a}\right)$, intensity of net energy input, and rate of convective vapour removal from the wet surface. The most widely used methods for PE estimation are derived from the Penman (1948) method which incorporates both energy balance and aerodynamic considerations. Based on the Penman method, evaporation was classified into two components: mass transfer (or convective) evaporation which is a function of wind speed and deficit of vapour pressure $\left(e_{s}-e_{a}\right)$, and radiative evaporation which is a function of net solar radiation density and latent heat of vaporisation. Both convective and radiative evaporation are related to air temperature.

The Penman method and its variants require climatic input parameters, such as solar radiation, humidity and wind speed, that are often not readily available, especially at remote mine sites where meteorological data is scarce. Blaney and Criddle (1950) calculated $\mathrm{ET}_{\mathrm{o}}$ from a monthly consumptive-use factor (f), mean monthly $\mathrm{T}_{\mathrm{a}}$, and percentage of total annual daylight hours (p) occurring during the studied months. This method was first developed for estimation of crop water requirement in western USA and later applied world-wide with variable results (Wright, 1990). Because $T_{a}$ records are often available, the use of $T_{a}$ as a surrogate for net radiation and deficit of vapour pressure $\left(\mathrm{e}_{\mathrm{s}}-\mathrm{e}_{\mathrm{a}}\right)$ greatly simplifies the calculation. However, the simplification requires three implicit monthly constants: (1) albedo; (2) the partition between latent heat of evaporation and sensible heat, or Bowen Ratio; and (3) the convective heat transfer, i.e. energy transfer due to strong horizontal moisture and temperature gradients. Of the above three inputs, only the last varies significantly on a local scale when the method is applied to different parts of the world. This provides reasonable technical grounds for the use of an empirical method based on temperature, such as the B-C equation.

\subsection{Original B-C method}

The B-C method always refers to mean monthly values, both for temperature and for $\mathrm{ET}_{\mathrm{o}}$. The computation includes three steps (Brouwer and Heibloem, 1986):

\section{Step 1 Determine the mean monthly temperature: $T_{\text {mean }}\left({ }^{\circ} \mathrm{C}\right)$}

If, in a local meteorological station, mean daily temperatures is measured, $T_{\text {mean }}$ is the average of the mean daily temperatures. If the minimum and maximum daily temperatures are measured, the mean daily temperature is the average of these two.

\section{Step 2 Determine the mean daily percentage of annual daytime hours: $p$}

The value of $\mathrm{p}$ is estimated based on latitude of the site, following Table 2. 
Table 2 Mean daily percentage (p) of annual daytime hours for different latitudes

\begin{tabular}{lccccccccccccc}
\hline Latitude & North & Jan & Feb & Mar & Apr & May & Jun & Jul & Aug & Sep & Oct & Nov & Dec \\
& South & Jul & Aug & Sep & Oct & Nov & Dec & Jan & Feb & Mar & Apr & May & Jun \\
\hline $60^{\circ}$ & .15 & .20 & .26 & .32 & .38 & .41 & .40 & .34 & .28 & .22 & .17 & .13 \\
$55^{\circ}$ & & .17 & .21 & .26 & .32 & .36 & .39 & .38 & .33 & .28 & .23 & .18 & .16 \\
$50^{\circ}$ & & .19 & .23 & .27 & .31 & .34 & .36 & .35 & .32 & .28 & .24 & .20 & .18 \\
$45^{\circ}$ & .20 & .23 & .27 & .30 & .34 & .35 & .34 & .32 & .28 & .24 & .21 & .20 \\
$40^{\circ}$ & .22 & .24 & .27 & .30 & .32 & .34 & .33 & .31 & .28 & .25 & .22 & .21 \\
$35^{\circ}$ & .23 & .25 & .27 & .29 & .31 & .32 & .32 & .30 & .28 & .25 & .23 & .22 \\
$30^{\circ}$ & .24 & .25 & .27 & .29 & .31 & .32 & .31 & .30 & .28 & .26 & .24 & .23 \\
$25^{\circ}$ & .24 & .26 & .27 & .29 & .30 & .31 & .31 & .29 & .28 & .26 & .25 & .24 \\
$20^{\circ}$ & .25 & .26 & .27 & .28 & .29 & .30 & .30 & .29 & .28 & .26 & .25 & .25 \\
$15^{\circ}$ & .26 & .26 & .27 & .28 & .29 & .29 & .29 & .28 & .28 & .27 & .26 & .25 \\
$10^{\circ}$ & .26 & .27 & .27 & .28 & .28 & .29 & .29 & .28 & .28 & .27 & .26 & .26 \\
$5^{\circ}$ & .27 & .27 & .27 & .28 & .28 & .28 & .28 & .28 & .28 & .27 & .27 & .27 \\
$0^{\circ}$ & .27 & .27 & .27 & .27 & .27 & .27 & .27 & .27 & .27 & .27 & .27 & .27 \\
\hline
\end{tabular}

Step 3 Calculate ET

$\mathrm{ET}_{\mathrm{o}}$ is determined based on the Equation:

$$
\mathrm{ET}_{\mathrm{o}}(\mathrm{mm} / \text { day })=\mathrm{p} \times\left(0.46 \mathrm{~T}_{\text {mean }}+8\right)
$$

\subsection{Modified B-C method}

The original B-C method was developed in the 1950s for estimating consumptive use by irrigated crops in the western United States, where the climates are moderate. Modification to the original B-C method is based on observed meteorological data at Barrick sites. Barrick is the world's pre-eminent gold producer, with a portfolio of 27 operating mines and 10 advanced exploration and development projects located across five continents. Barrick's geographical coverage allows us to enhance $\mathrm{ET}_{\mathrm{o}}$ estimates at extreme climate conditions. Locations of Barrick operational/project sites are shown on Figure 1. 


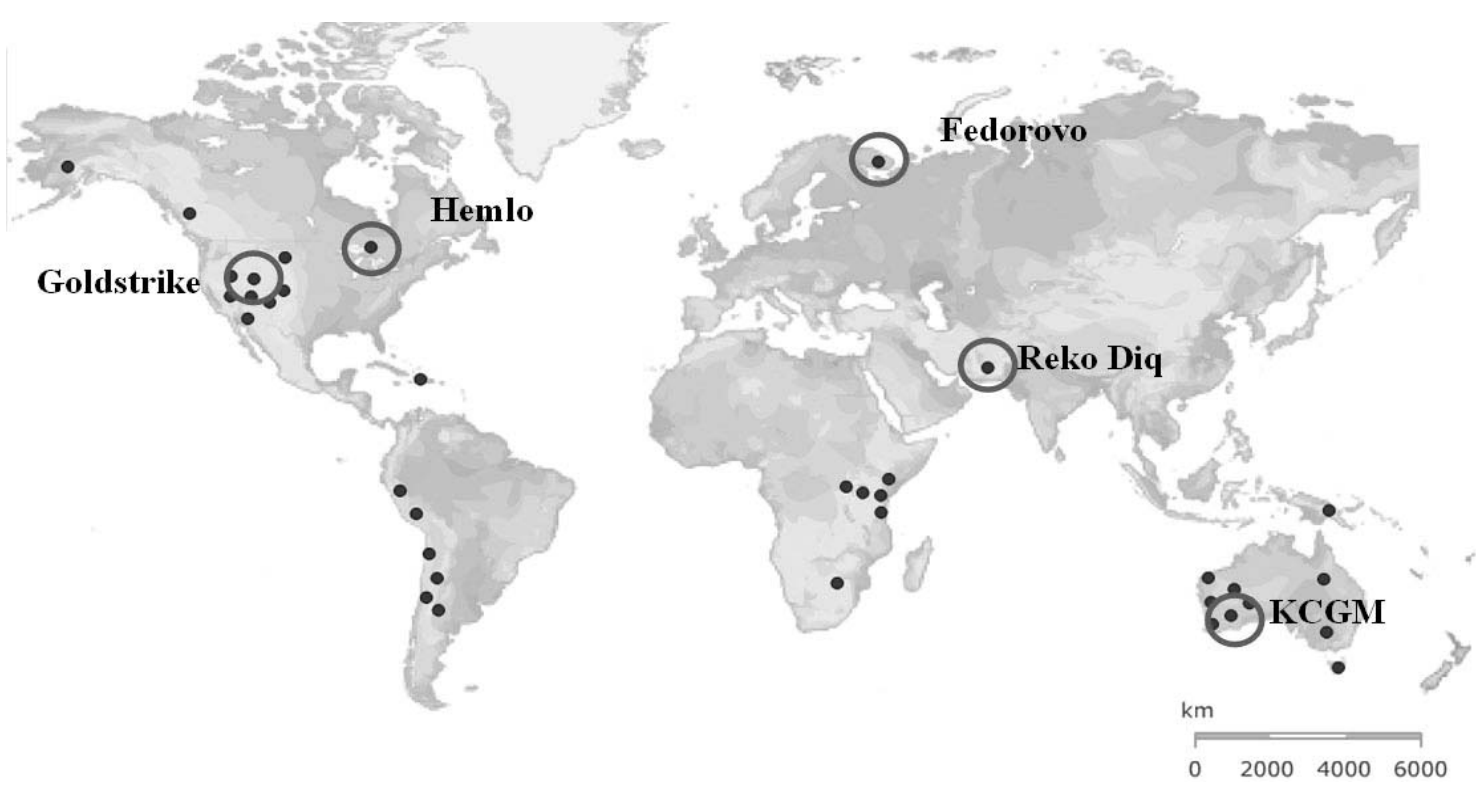

Figure 1 Barrick's operational/project sites around the world. Sites circled are used for calibration

Five Barrick sites, representing a range of humid to arid climates, were chosen for model calibration (Figure 1). The modified B-C equation was calibrated to reported values for Penman-Monteith $E T_{o}$ from automated weather stations. A brief description of each site follows:

- Reko Diq: The project is located near the western tip of Balochistan Province in southwest Pakistan, bordering Iran and Afghanistan. The climate at Reko Diq is arid. There are rare, but high intensity summer storms. The climate (annual average) of the site is hot $\left(23^{\circ} \mathrm{C}\right)$ and dry $(32 \mathrm{~mm} / \mathrm{y}$ of rainfall, $25 \% \mathrm{RH})$. The site experiences very strong evaporation $\left(\mathrm{ET}_{\mathrm{o}}=3,900 \mathrm{~mm} / \mathrm{y}\right)$ and high winds (annual wind speed of $7.8 \mathrm{~m} / \mathrm{s}$ ).

- Kalgoorlie Consolidated Gold Mines (KCGM): The mine is located near the city KalgoorlieBoulder, which is approximately $600 \mathrm{~km}$ east of Perth, capital of Western Australia. The climate at KCGM is semi-arid, with high intensity storms being common. Annual rainfall ranges from a low of $110 \mathrm{~mm}$ to a high of $530 \mathrm{~mm}$ with an average of about $270 \mathrm{~mm}$. The site is characterised by warm to hot summers and mild winters. Temperatures rarely fall below $0^{\circ} \mathrm{C}$. Annual evaporation $\left(\mathrm{ET}_{\mathrm{o}}\right)$ is about $2,650 \mathrm{~mm}$, ten times the average annual rainfall.

- Goldstrike: The mine is located near Elko in north central Nevada, USA. The climate at Goldstrike is between normal and semi-arid. The winter is cold and summer is hot. Average annual precipitation ranges between 200 and $380 \mathrm{~mm}$ with half of the precipitation occurring as winter snowfall. Average annual evaporation $\left(\mathrm{ET}_{\mathrm{o}}\right.$ ) is about $1,400 \mathrm{~mm}$. Average annual wind speed is $2.6 \mathrm{~m} / \mathrm{s}$, which is classified as light breeze based on World Meteorological Organization (WMO) standards.

- Hemlo: The mine is located approximately $37 \mathrm{~km}$ east of Marathon, in the District of Thunder Bay, Ontario, Canada. The climate at Hemlo is semi-humid. The climate is cold with an average annual air temperature of $1.5^{\circ} \mathrm{C}$. The average annual precipitation is $760 \mathrm{~mm}$, and annual evaporation $\left(\mathrm{ET}_{\mathrm{o}}\right)$ is approximately $510 \mathrm{~mm}$.

- Fedorovo: The project is located near the centre of the Kola Peninsula, in Lovozero District, Murmansk Region, Russia. The climate at Fedorovo is humid. The climate of the site is formed under the action of the Arctic air masses and surrounding Barents and White seas. Therefore, the climate is cold with an average annual air temperature of $-1{ }^{\circ} \mathrm{C}$. The average annual precipitation is about $540 \mathrm{~mm}$, with the cold (November-April) and warm (May-October) periods accounting for $35 \%$ and $65 \%$, respectively, of the annual total. Annual average RH is high (85\%) and annual $E T_{o}$ is about $320 \mathrm{~mm}$. Due to the high humidity and plentiful water, the actual evaporation (including snow sublimation) is nearly identical to PE.

Monthly temperature and $E T_{o}$ at each of the five sites are listed in Table 3. 


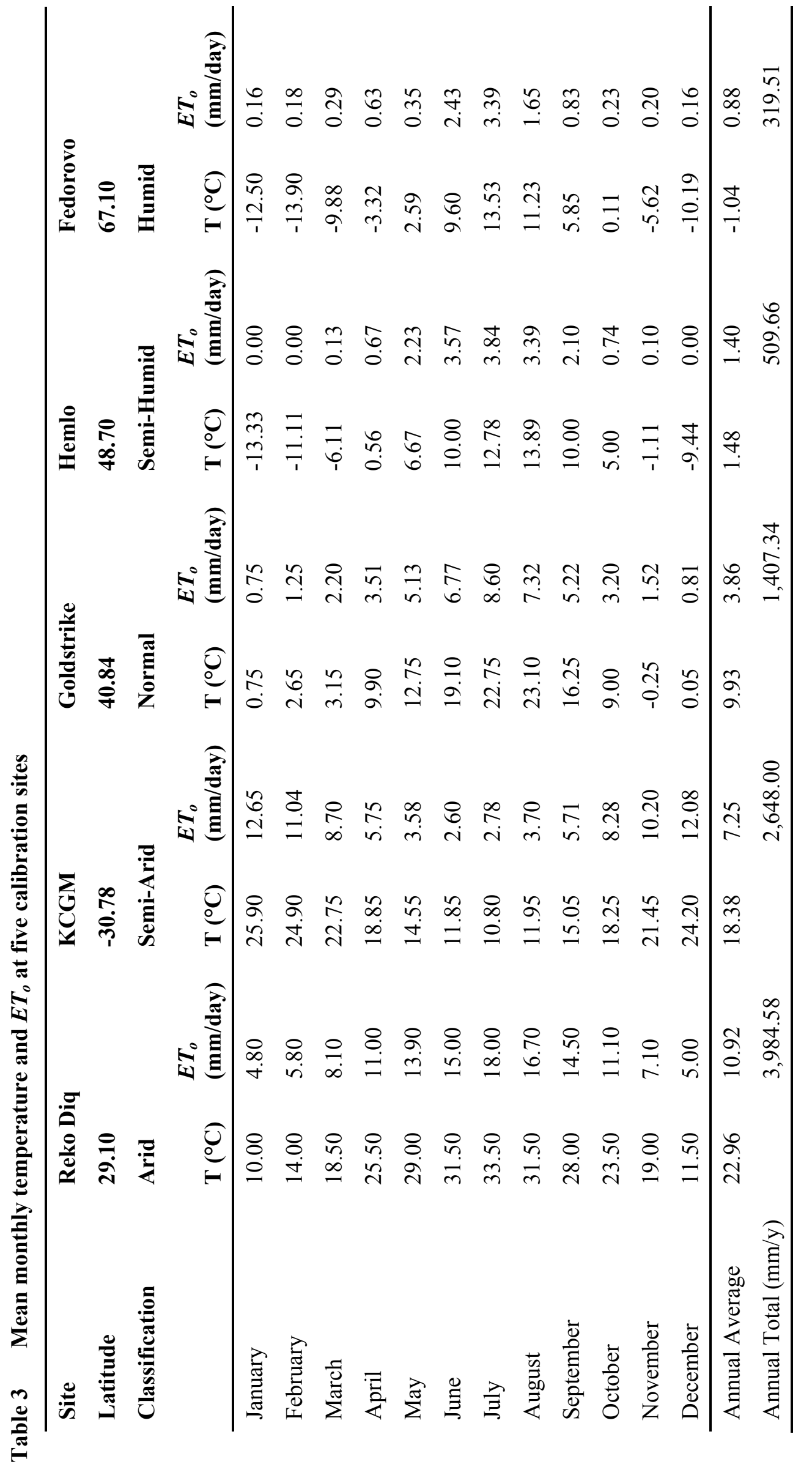


By applying the monthly temperatures in Table 3 to the original B-C equation, it was found that the B-C method can provide accurate estimates for moderate climates such as Goldstrike. Under more extreme climatic conditions the B-C method is inaccurate: in windy, dry, sunny areas such as Reko Diq the $\mathrm{ET}_{\mathrm{o}}$ is underestimated by up to 50 per cent, while in calm, humid, cloudy areas the $\mathrm{ET}_{\mathrm{o}}$ is overestimated by up to 170 per cent. This observation is in agreement with FAO studies (Brouwer and Heibloem, 1986).

The modified B-C method uses an adjustment factor $\mathrm{K}$ which is determined by the ratio of the observed Penman-Montieth $E T_{o}$ to $\mathrm{ET}_{o}$ computed using the original B-C equation. The linear relationship between $\mathrm{K}$ and the $\mathrm{B}-\mathrm{C}$ equation $\mathrm{ET}_{\mathrm{o}}$ is illustrated on Figure 2.

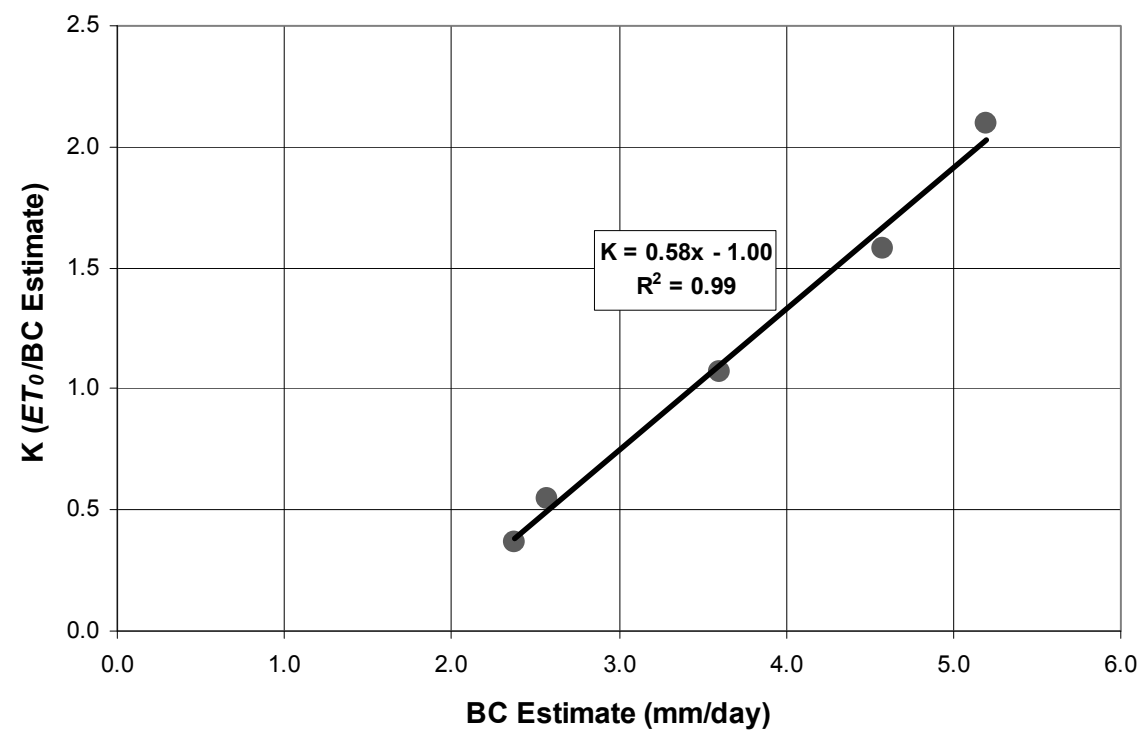

Figure 2 Adjustment factor $\mathrm{K}$ to B-C method based on five Barrick sites

The modified B-C method adds one more step to correct the original B-C equation.

Step 4 Compute ET $T_{o a d j}$, multiplying ET $T_{o}$ by $K$

$$
\mathrm{ET}_{\text {oadj }}(\mathrm{mm} / \text { day })=\mathrm{K} \times \mathrm{ET}_{\mathrm{o}}=\left(0.58 \times \mathrm{ET}_{\mathrm{o}}-1\right) \times \mathrm{ET}_{\mathrm{o}}
$$

Where $\mathrm{ET}_{\mathrm{o}}$ is calculated in Step 3 above using the original $\mathrm{B}-\mathrm{C}$ method and $\mathrm{K}$ is the adjustment factor.

As part of the method calibration, the monthly $\mathrm{ET}_{\text {oadj }}$ were compared to the Penman-Monteith $E T_{o}$ calculated from data recorded at the five sites. The results show that the observed seasonal trends are well represented using the revised B-C method (Table 4). 


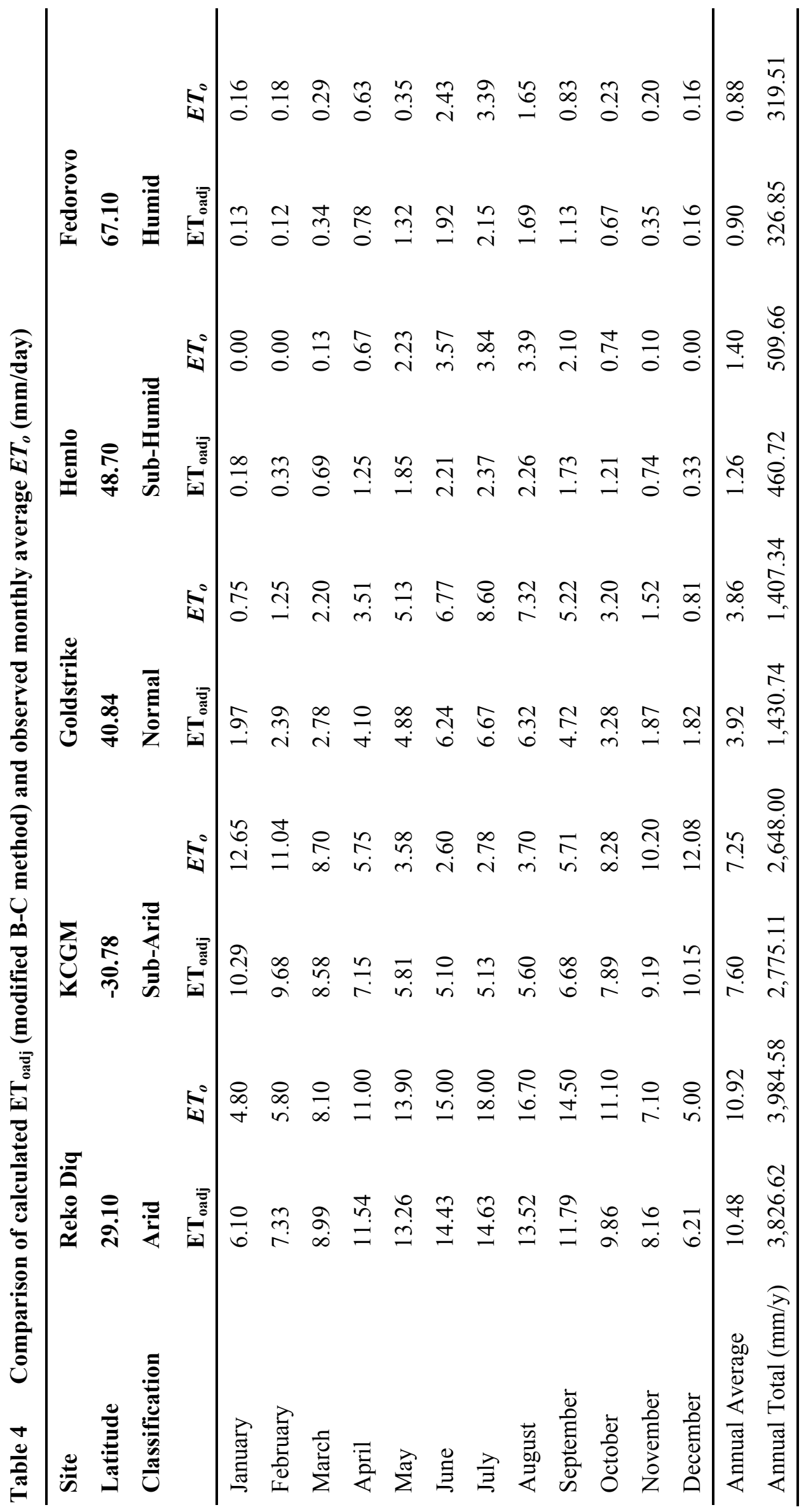




\section{$2.4 \quad$ Validation of the modified B-C method}

Validation tests model accuracy by using inputs not previously included in the calibration. Eight Barrick sites were used for validation: five from North America, one from South America, one from Australia and one from Africa.

Figure 3 illustrates the relationship between measured annual $E T_{o}$ and estimated annual $\mathrm{ET}_{\text {oadj }}$ using the modified B-C method.

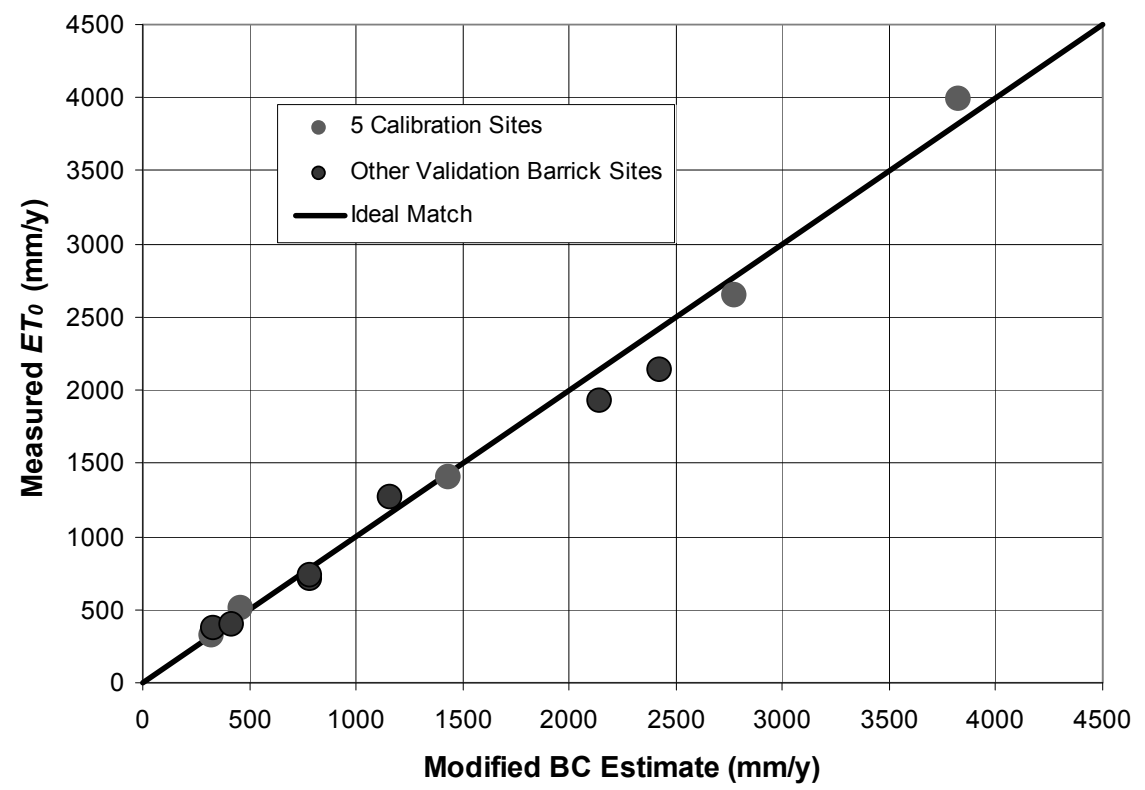

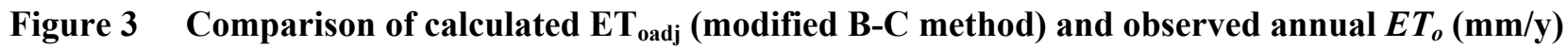

The modified method worked well for all validation sites except the one in Africa near the equator (Buzwagi, not illustrated on Figure 3). The mine is situated in the tropical region south of Lake Victoria in Tanzania. The climate is controlled by a tropical monsoon pattern which results in distinct dry and wet seasons. Despite the drastic changes in seasonal rainfall and humidity, average monthly air temperature remains within a narrow range between 24 and $26^{\circ} \mathrm{C}$ throughout the year. Therefore, the modified B-C method should be used with caution for equatorial tropical sites where temperatures do not change much, and changes in $\mathrm{ET}_{\mathrm{o}}$ simply do not correspond to changes in temperature.

In order to demonstrate the degree of improvement of the proposed modified $\mathrm{B}-\mathrm{C}$ method, estimated annual $\mathrm{ET}_{\mathrm{o}}$ using the original, unmodified $\mathrm{B}-\mathrm{C}$ method were compared to the measured annual $E T_{o}$ at the same 12 sites used for model calibration and validation (Figure 4). It was found that the original B-C method only provides reasonable estimates for moderate climates with $E T_{o}$ between $1,000-1,500 \mathrm{~mm} / \mathrm{y}$. On the one hand, it significantly underestimates $\mathrm{ET}_{\mathrm{o}}$ at dry climate sites. On the other hand, it overestimates $\mathrm{ET}_{\mathrm{o}}$ at wet climate sites. This finding is in full agreement with FAO studies (Brouwer and Heibloem, 1986). 


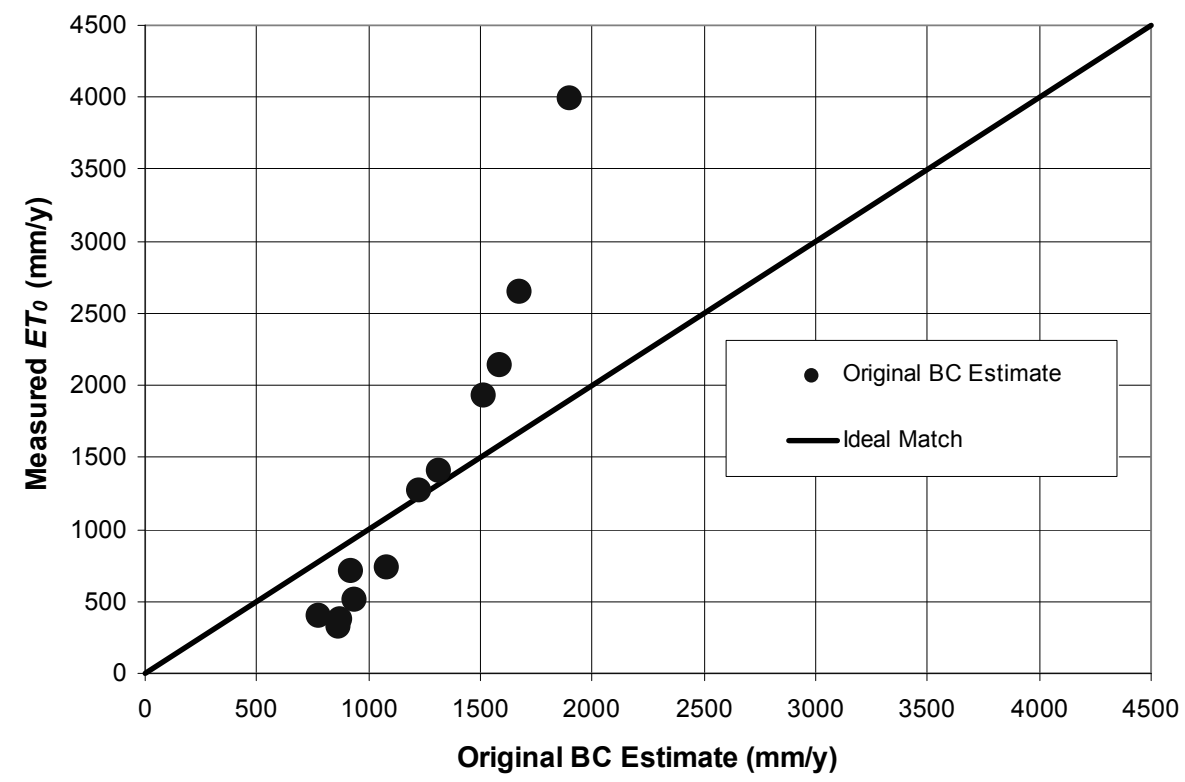

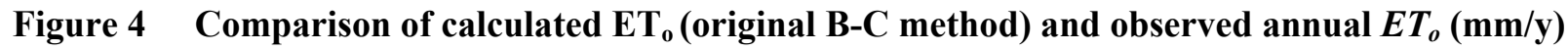

\section{Conclusions}

Potential evaporation (PE) or potential evapotranspiration $\left(\mathrm{PET}, \mathrm{ET}_{\mathrm{o}}\right.$ ) is one of the fundamental elements in the hydrologic cycle. This paper presents a modification to the original B-C method, using observed meteorological data at Barrick sites. The modified method is able to estimate PE with improved accuracy and is applicable to a wide range of climate conditions. Among the calibration and validation sites, measured $E T_{o}$ varies from $300-4,000 \mathrm{~mm} / \mathrm{y}$. Annual average RH varies from $25-85$ per cent. Annual wind speed varies from calm wind $(2 \mathrm{~m} / \mathrm{s})$ to strong wind $(8 \mathrm{~m} / \mathrm{s})$, and site elevations range from 400-4,000 m above sea level.

It is believed that the proposed approach will provide a simple but accurate PE (PET) estimating tool for mining engineers and hydrologists when dealing with site-wide water management during life-of-mine and in closure.

\section{Acknowledgements}

The authors would like to thank their employer, Barrick Gold Corporation, for allowing us to publish the results of this study.

\section{References}

Al-Darir, A.N. and Aldoubiat, M. (2005) The optimizing model of potential evaporation in North Syria, Ninth International Water Technology Conference, IWTC9, 17-20 March 2005, Sharm El-Sheikh, Egypt, pp. 41-50.

Blaney, H.F. and Criddle, W.D. (1950) Determining water requirement in irrigated areas from climatological data, Soil Conservation Service Technical Publication No. 96, Washington DC, US Department of Agriculture, 48 p.

Brouwer, C. and Heibloem, M. (1986) Irrigation water management: irrigation water needs, Chapter 3, FAO online document, viewed on 11 July 2009, http://www.fao.org/docrep/S2022E/s2022e00.HTM

Brustaert, W. (1982) Evaporation into the atmosphere - theory, history and applications, D. Reidel Publishing Company, London, England, 214 p.

deBruin, H.A.R. (1978) A simple model for shallow lake evaporation, Journal of Applied Meteorology, Vol. 17, pp. 1132-1134

FAO (1998) Crop evapotranspiration - guidelines for computing crop water requirements - FAO Irrigation and Drainage Paper 56, FAO online document, viewed on 11 July 2009, http://www.fao.org/docrep/X0490E/X0490E00.htm

Harmsen, E.W., Gonzalez, P.A. and Winter, A. (2003) Estimating long-term average monthly evapotranspiration from pan evaporation data at seven locations in Puerto Rico, NoAA-Crest/NASA-EpscoR Joint Symposium for Climate Studies, University of Puerto Rico - Mayaguez Campus, Puerto Rico, January 10-11, 2003, 7 p. 
Hill, R.W., Johns, E.L. and Frevert, D.K. (1983) Comparison of equations used for estimating agricultural crop evapotranspiration with field research, Bureau of Reclamation, US Department of the Interior, E\&R Center, Denver, Colorado, $41 \mathrm{p}$.

Jensen, M.E. (ed) (1973) Consumptive use of water and irrigation water requirements, American Society of Civil Engineers, New York, 215 p.

Monteith, J.L. (1965) Evaporation and environment, Symposia of the Society for Experimental Biology, Vol. 19, pp. 205-234.

Papadopoulou, E., Varanou, E., Baltas, E., Dassaklis, A. and Mimikou, M. (2003) Estimating potential evapotranspiration and its spatial distribution in Greece using empirical methods, Eighth International Conference on Environmental Science and Technology, Lemnos Island, Greece, 8-10 September 2003, pp. 650658.

Penman, H.L. (1948) Natural evaporation from open water, bare soil, and grass, Proceedings of the Royal Society, London, A193, pp. 120-145.

Stewart, R.B. and Rouse, W.R. (1976) A simple method for determining the evaporation from shallow lakes and ponds, Water Resources Research, Vol. 12, pp. 623-628.

Wright, J.L. (1990) Estimating crop evapotranspiration, evapotranspiration and irrigation water requirements, M.E. Jensen, R.D. Burman and R.G. Allen (ed), American Society of Civil Engineers, New York, pp. 112-131. 